مطالعه اثر تنش شورى بر مؤلفههاى جوانهزنى ارقام مختلف كندم (Triticum aestivum)

$$
\begin{aligned}
& \text { على نامور '،"، رئوف سيدشريفى'، هاشم هادى } \\
& \text { ' دانشجوى دكترى فيزيولوزى گياهان زراعى دانشخاه اروميه }
\end{aligned}
$$

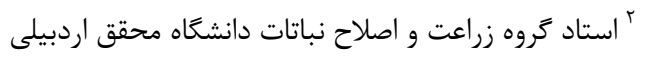

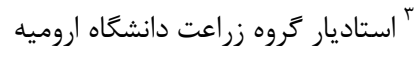

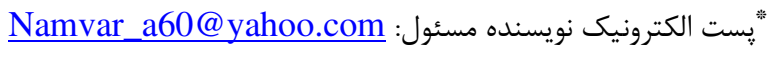

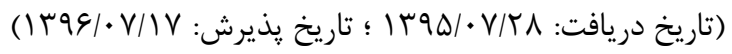

جكيده

بلهمنظور بررسى واكنش ارقام مختلف تَندم به تنش شورى در در مرحلهى جوانهزنى، آزمايشى بهصورت

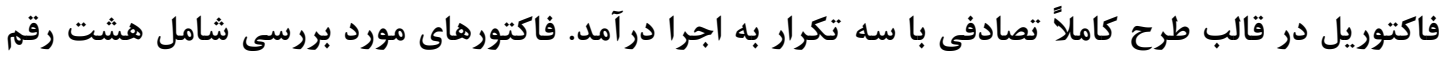

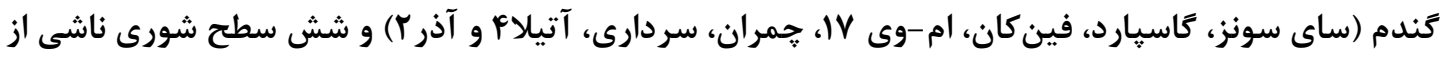

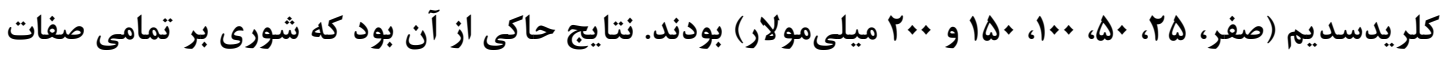

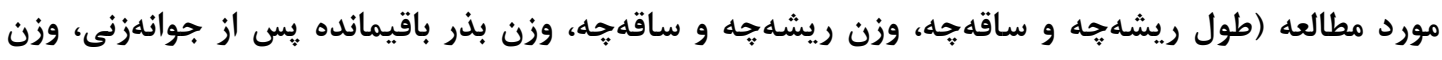

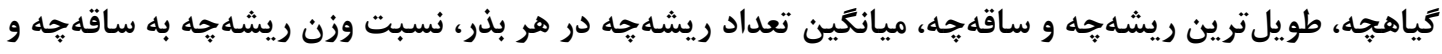

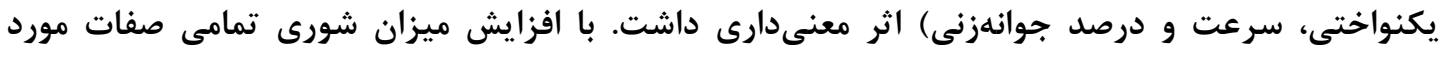

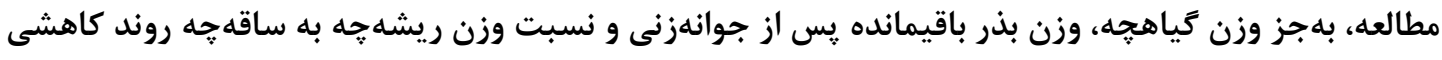

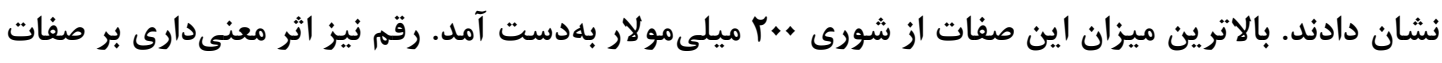

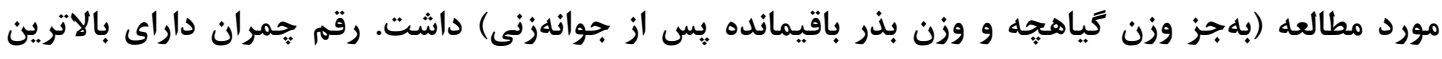

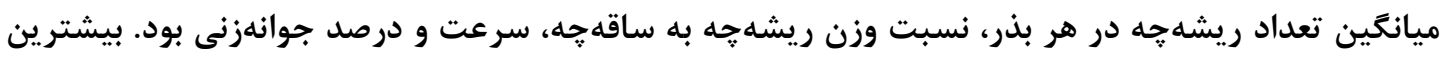

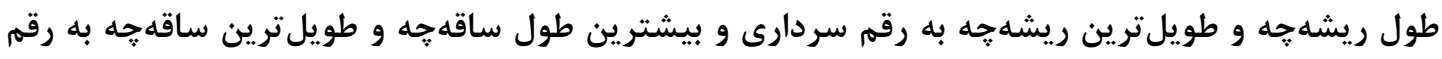

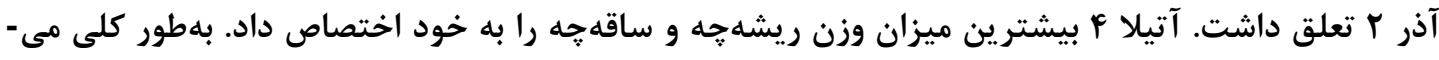

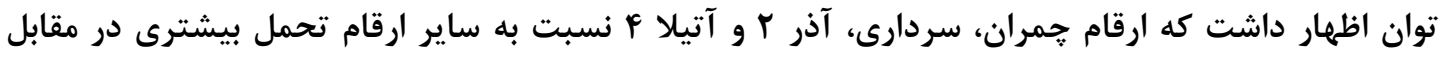
تنش شورى از خود نشان دادند. وازههاى كليدى: ارقام كندم، تنش شورى، تعداد ريشهجه، وزن بذر باقيمانده پس از جوانهزنى

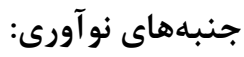

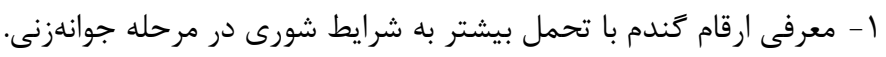

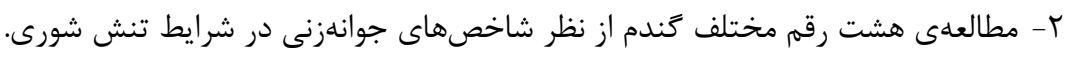

DOI: $10.29252 /$ yujs.4.2.1

CrossMark 
يكنواختى جوانهزنى عددى منفى است كه مقادير پايين

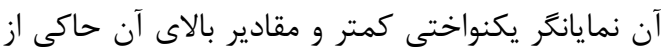
يكنواختى بيشتر جوانهزنى مىباشد (سلطانى و همكاران،

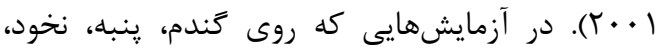

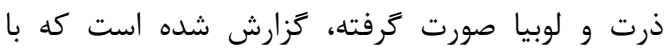
افزايش شورى آب آبيارى، درصد و سرعت جوانهزنى،

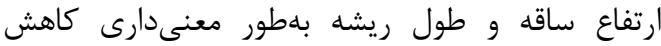

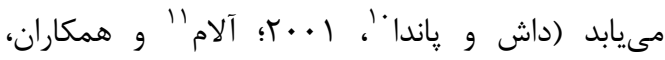

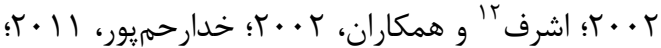

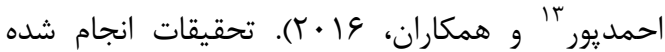
روى گياهان زراعى مختلف بيانكر اين واقعيت است كه

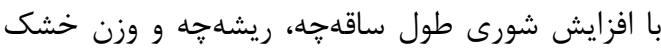

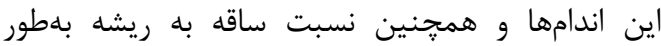

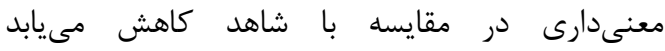

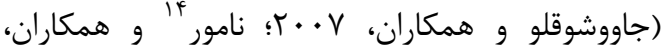

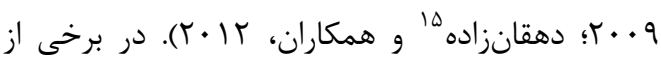
تحقيقات گزارش شده است كه طول ساقهجه نسبت به ريشهجه بيشتر تحت تأثير تنش شورى قرار مى نى سيرد

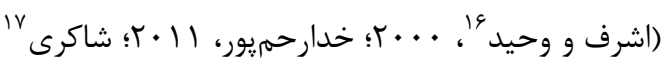

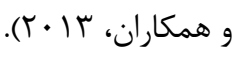

تفاوت در قدرت تحمل به شورى نهتنها در ميان جنسها و گونهها، بلكه حتى در داخل يك گونه نيز مشاهده مىشود. ميزان كاهش جوانهزنى و رشد رياه تحت شرايط شورى به رقم، تركيب نمك، غلظت نمى مئى

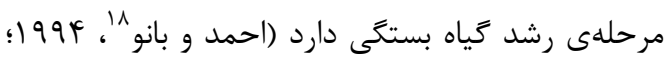

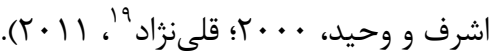
كَندم بهعنوان يك غلهى مهرم، غذاى بسيارى از مردم كشورهاى در حال توسعه محسوب مى گردد و از سوى ديخر، در بين غلات بيشترين سطح كشت را به

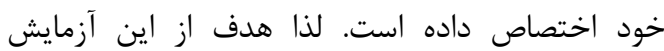
بررسى اثرات تنش شورى ناشى از كلريدسديم كه جزء

\footnotetext{
${ }^{10}$ Dash and Panda

${ }_{11}$ Alam

${ }^{12}$ Ashraf

${ }^{13}$ Ahmadpour

${ }^{14}$ Namvar

${ }^{15}$ Dehganzadeh

${ }^{16}$ Ashraf and Wahid

${ }^{17}$ Shakeri

${ }^{18}$ Ahmad and Bano

${ }^{19}$ Gholinejhad
}

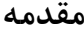

شورى يكى از مهلمترين مشكلات مناطق خشك و

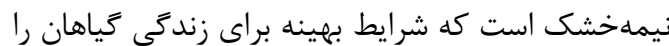

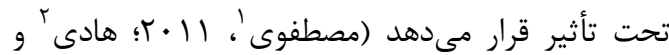

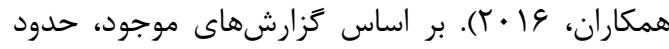

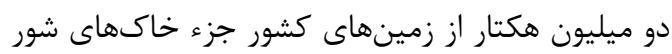
مىباشند. آبيارى بيش از حد با آب شور و زهكشى

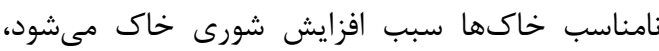
زيرا يس از تبخير و تعرق آب خالص از سطح خاك و كياه، غلظت املاح خاك افزايشيافته و اين امر موجب لهب كاهش يتانسيل آب و ايجاد تنشهای اسمزى إنى در زياه

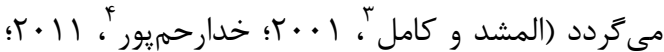

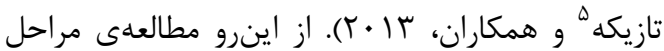
مختلف رشد كياهان زراعى در شرايط تنش شورى

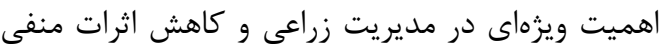
تنش بر رشد و توليد محصول گياهان زراعى دارد. يكى از مراحل حساس گَياهان به تنش شورى، مرحلهى

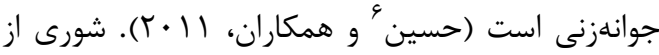
طريق كاهش يتانسيل آب و سميت يونهاى خاص از قبيل سديم و كلر و كاهش يونهاى غذايى مورد نياز نظير كلسيم و يتاسيم بر جوانهزنى بذر و رشد آن تأثير

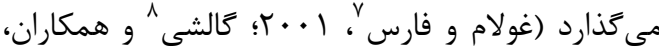

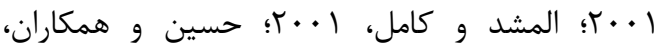

مطالعات متعددى نشان دادهاند كه درصد و سرعت جوانهزنى بذر با افزايش شورى كاهش مىيابد (غولام و

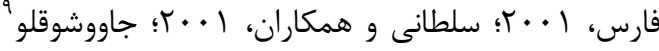

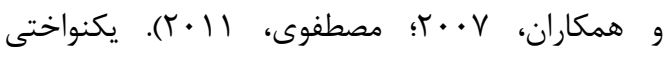

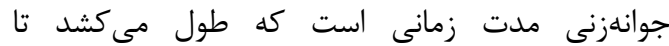
جوانهزنى از • ا درصد (D10) به · •9 درصد جوانهزنى

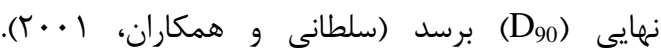

\footnotetext{
${ }^{1}$ Mostafavi

${ }^{2}$ Hadi

${ }^{3}$ El-Mashad and Kamel

${ }^{4}$ Khodarahmpour

${ }^{5}$ Tazikeh

${ }^{6}$ Hussain

${ }^{7}$ Ghoulam and Fares

${ }^{8}$ Galeshi

${ }^{9}$ Cavusoglu
} 
استفاده از روش درونيابى خطى بلهدست آمد. محاسبهى

اجزاى مذكور با استفاده از برنامهى كامِيوترى

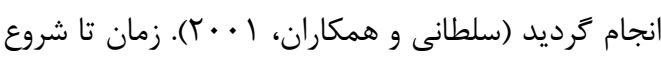
جوانهزنى، يكنواختى جوانهزنى و سرعت جوانهزنى بها صورت زير معين شدند: (ساعت) يكنواختى جوانهزنى (ساعت) = $=\mathrm{D}_{90}-\mathrm{D}_{10}$ 1/D $=1 / D_{50}$

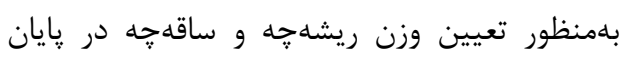

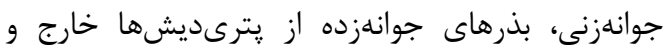

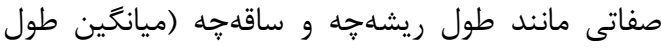

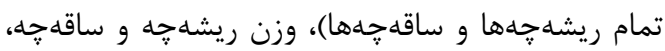
وزن بذر باقيمانده پِ از جوانهزنى و وزن كياهجه، طول طويلترين ريشهجه و ساقهجه، ميانكين تعداد ريشه در هر بذر و نسبت ريشه קه به ساقهجه اندازهيرى شدي براى محاسبهى وزن خشك ريشهجه و ساقهاته و بذر

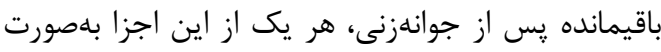

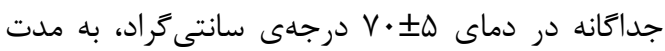

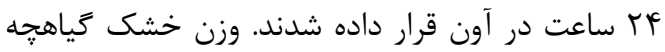

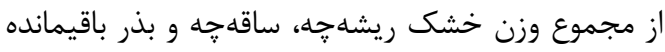
جس ارماز جوانهزنى بهدست آمد. براى تجزيهى واريانس دادهها، نرمافزار SAS بهكار برده شد و و مقايسهى

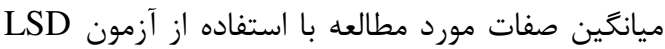
در سطح ه درصد انجام گرفت.

\section{نتايج و بحث}

نتايج حاصل از تجزيهى واريانس دادهها نشان داد

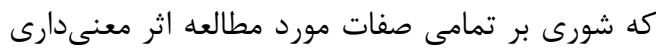

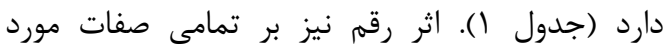

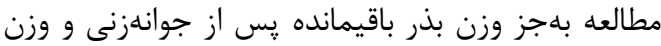

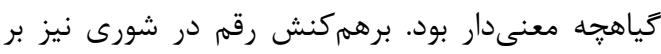
طول ريشهجه و ساقهجه، طول طويلترين ريشهاجه و

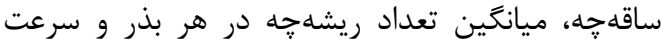

$$
\text { جوانهزنى معنى دار كرديد (جدول () ). }
$$

\section{طول ريشه ֶه و ساقه}

بررسى اثر متقابل رقم در شورى بر صفت طول ريشهجه بيانگر برترى رقم سردارى (در سطح شورى
نمكهاى غالب خاكهاى شور در مناطق خشك و نيمهخشك مىباشد، بر مؤلفهاى جوانهزنى و ر رشد كياهجه ارقام كَندم و شناسايى متحمل ترين رقم نسبت به شورى بود.

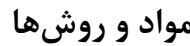

بلمنظور تعيين اثر سطوح مختلف شورى بر آناري جوانهزنى ارقام مختلف كَندم، آزمايشى بلهصورت

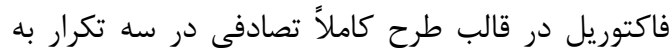

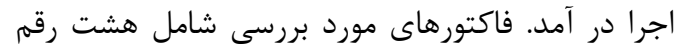

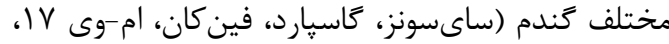

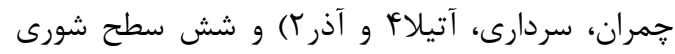

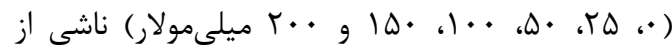

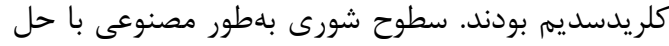

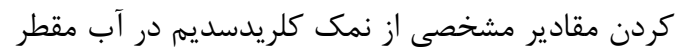
تهيه كرديد. براى سطح صفر يا شاهد از آب مقطر

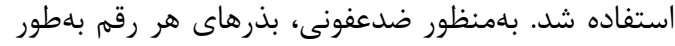

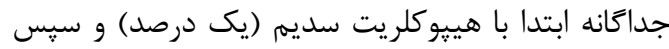

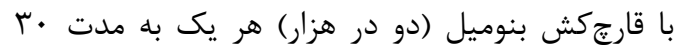
ثانيه سترون و بعد از هر مرحله با آب مقطر بلهطور كامل

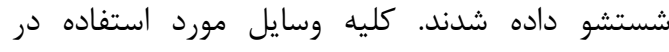
آزمايش ضدعفونى شدند. تعداد • r عدد بذر ضدعفونى شده از هر رقم در داخل هر يترىديش روى كاغذ صافى

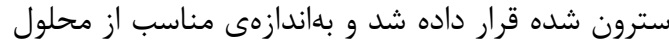

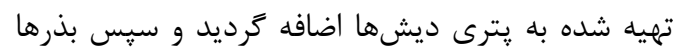

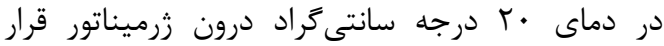

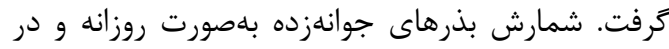

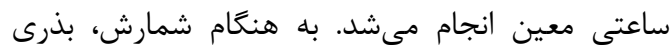

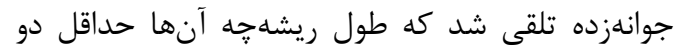
ميلىمتر بود (حسين و همكاران، (1) (†). شمارش تا

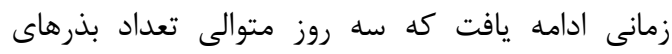
جوانهزده در هر يترىديش ثابت بماند. براى ارزيابى اجزاى جوانهزنى، منحنى پِيشرفت

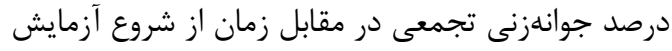

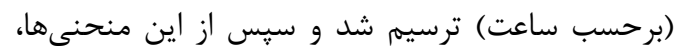

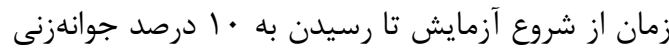

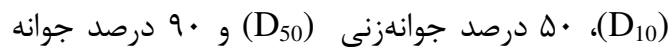
زنى 
گرفته و با بروز تنش، نوع فعاليتها و تركيباتى كه

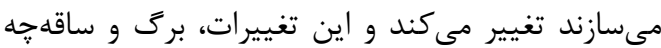

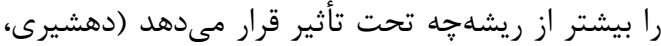

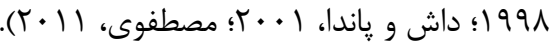

وزن ريشه پُه، وزن ساقه جه و نسبت وزن ريشه به ساقه جهـ

با توجه به نتايج جدول r مشاهده مىشود كه رقم آتيلا f بيشترين و رقم فين كان، از كمترين وزن ريشهجه برخوردار بودند. در مورد وزن ساقهجه نيز ارقام آتيلا

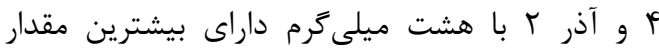
بودند. كمترين وزن ساقهجه به رقم ساىسونز مربوط مىشد كه البته اختلاف معنىدارى با رقم فين كان

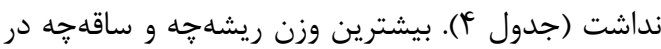

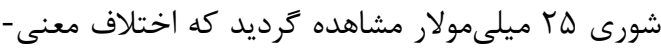

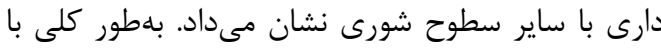
افزايش ميزان شورى وزن ريشهُ

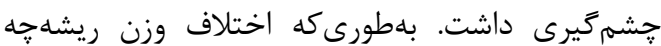

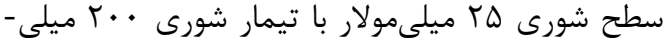

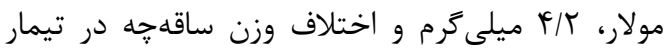
شورى له ميلى مولار با سطح شورى · ·r ميلى مولار، 9/r ميلى ساقه קه در اثر افزايش غلظت شورى، امرى طبيعى بوده و نتايج محققان ديگر نيز اين امر را ثابت كرده است

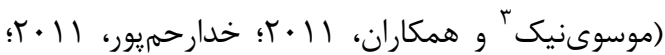

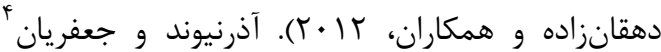

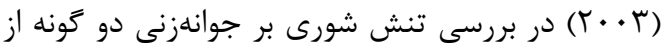

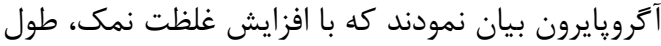

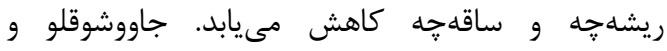

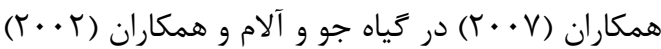
در گَندم نتايج مشابهى گزارش نمودند.

\footnotetext{
${ }^{3}$ Moussavi-Nik
}

${ }^{4}$ Azarnivand and Jafarian
S ميلىمولار) نسبت به ساير ارقام مورد مطالعه بود.

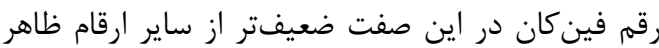
گرديد. در بالاترين سطح شورى رقمم آذر ب داراى بالاترين طول ريشهجه و رقم ساىسونز داراى پايينترين

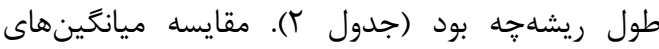
برهمكنش تيمارها بر طول ساقهجه نشان داد كه رقم مئه فين كان در سطح شورى اول (شاهد) و رقمهاى سردارى

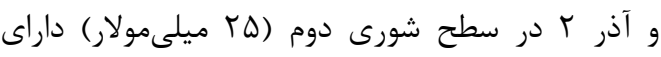
بيشترين طول ساقه ֶه بودند، هرجند كه اختلاف معنى دارى ميان آنها نبود. در سطوح بالاى شورى، ارقام ام-

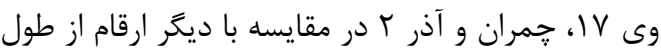

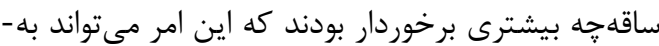
عنوان يك صفت مطلوب مطرح باشد (جدول بـ).

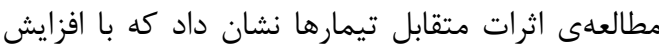

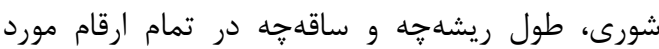
آزمايش كاهش مىيابد. اختلاف اين دو صفت در سطح شورى • إ ميلىمولار و بالاتر با تيمار شاهد كاملاً

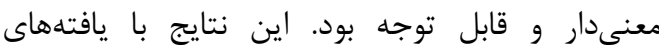

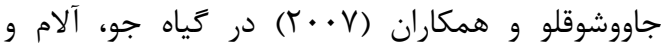

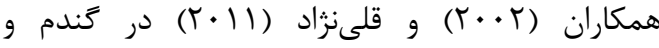
احمديور و همكاران (ع • (广) در نخود مطابقت دارد. در ضمن نتايج بهدست آمده نشان داد كه طول ساقه ته بيشتر از طول ريشهجه تحت تأثير شورى قرار مى نيرد كه اين يافته با تحقيقات بسيارى از محققان مطابقت

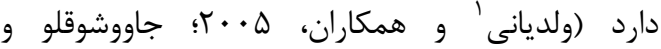

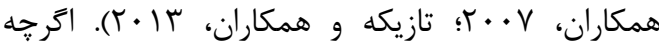
علت اين يديده هنوز بهدرستى مشخص نشده است، ولى له برخى معتقدند كه فشار تورزسانس لازم براى انجام يافتن رشد در اندامهاى مختلف، متفاوت مىباشد. به-

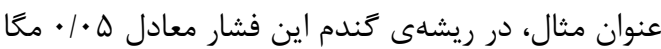

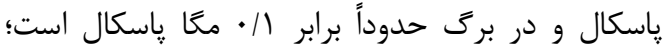

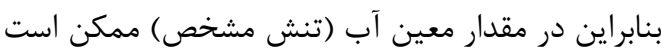

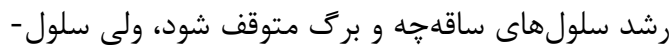

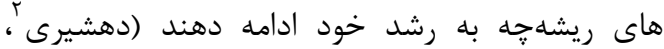
1991). در ضمن تحمل اندامهايى كه در راستاى سنتز مواد ديوارهاى فعاليت دارند، تحت تأثير كمآبى قرار

\footnotetext{
${ }^{1}$ Valadiani

${ }^{2}$ Dehshiri
} 


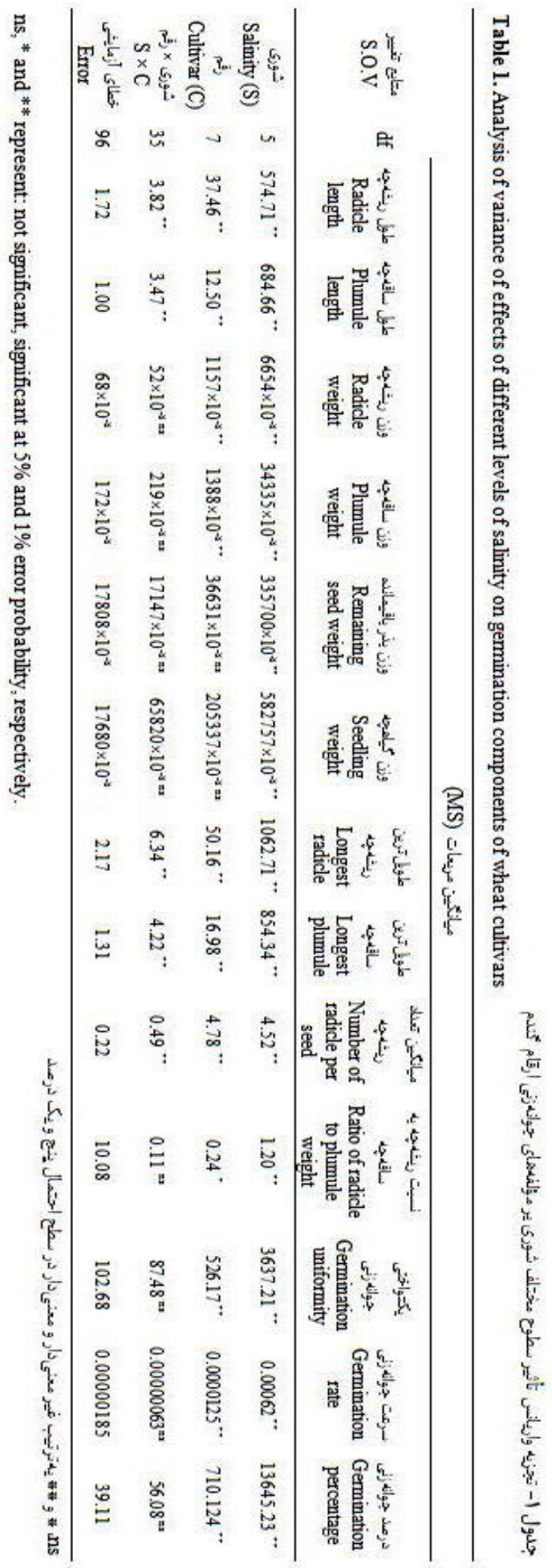




$$
\text { جدول r - مقايسه ميانگين اثر متقابل شورى در رقم براى صفت طول ريشهجه (سانتىمتر). }
$$

Table 2. Mean comparison of interaction effects of salinity and wheat cultivars on radicle length (cm).

\begin{tabular}{ccccccccc}
\hline $\begin{array}{c}\text { شور } \\
\text { Salinity (mM) }\end{array}$ & Saysons & Gaspard & Finkan & MV-17 & Chamran & Sardari & Atila-4 & Azar-2 \\
\hline 0 (control) & $10.06 \mathrm{e}-\mathrm{h}$ & $10.50 \mathrm{~d}-\mathrm{g}$ & $9.24 \mathrm{~g}-\mathrm{j}$ & $13.40 \mathrm{bc}$ & $12.13 \mathrm{~cd}$ & $15.08 \mathrm{ab}$ & $12.46 \mathrm{~cd}$ & $12.87 \mathrm{c}$ \\
25 & $8.23 \mathrm{~h}-\mathrm{k}$ & $10.58 \mathrm{~d}-\mathrm{g}$ & $9.72 \mathrm{f}-\mathrm{j}$ & $13.44 \mathrm{bc}$ & $11.42 \mathrm{c}-\mathrm{f}$ & $16.88 \mathrm{a}$ & $12.94 \mathrm{c}$ & $11.92 \mathrm{c}-\mathrm{e}$ \\
50 & $8.00 \mathrm{i}-\mathrm{k}$ & $8.77 \mathrm{~g}-\mathrm{j}$ & $6.35 \mathrm{kl}$ & $11.40 \mathrm{c}-\mathrm{f}$ & $9.21 \mathrm{~g}-\mathrm{j}$ & $12.91 \mathrm{c}$ & $10.01 \mathrm{e}-\mathrm{i}$ & $11.59 \mathrm{c}-\mathrm{f}$ \\
100 & $4.96 \mathrm{~lm}$ & $4.00 \mathrm{mn}$ & $4.76 \mathrm{~lm}$ & $7.43 \mathrm{jk}$ & $5.05 \mathrm{~lm}$ & $7.67 \mathrm{jk}$ & $6.24 \mathrm{kl}$ & $9.12 \mathrm{~g}-\mathrm{j}$ \\
150 & $1.03 \mathrm{op}$ & $1.33 \mathrm{op}$ & $1.51 \mathrm{op}$ & $1.91 \mathrm{op}$ & $1.84 \mathrm{op}$ & $2.06 \mathrm{n}-\mathrm{p}$ & $1.82 \mathrm{op}$ & $2.62 \mathrm{no}$ \\
200 & $0.53 \mathrm{p}$ & $0.61 \mathrm{op}$ & $0.68 \mathrm{op}$ & $1.05 \mathrm{op}$ & $1.05 \mathrm{op}$ & $1.10 \mathrm{op}$ & $1.21 \mathrm{op}$ & $2.22 \mathrm{n}-\mathrm{p}$ \\
\hline
\end{tabular}

ميانگينهاى داراى حداقل يك حرف مشترك بر اساس آزمون LSD در سطح ينج درصد اختلاف معنى دارى با يكديگر ندارند.

Means with same letters have no significant difference, based on LSD Test ( $\alpha=0.05)$.

جدول ب- مقايسه ميانگين اثر متقابل شورى در رقم براى صفت طول ساقهجه (سانتىمتر).

Table 3. Mean comparison of interaction effects of salinity and wheat cultivars on plumule length $(\mathrm{cm})$.

\begin{tabular}{ccccccccc}
\hline $\begin{array}{c}\text { Aو } \\
\text { Salinity (mM) }\end{array}$ & Saysons & Gaspard & Finkan & MV-17 & Chamran & Sardari & Atila-4 & Azar-2 \\
\hline 0 (control) & $10.53 \mathrm{i}-\mathrm{k}$ & $9.58 \mathrm{j}-1$ & $15.80 \mathrm{a}$ & $11.92 \mathrm{~d}-\mathrm{f}$ & $11.50 \mathrm{e}-\mathrm{i}$ & $13.33 \mathrm{~cd}$ & $11.62 \mathrm{e}-\mathrm{h}$ & $13.21 \mathrm{~cd}$ \\
25 & $10.39 \mathrm{~g}-\mathrm{j}$ & $11.40 \mathrm{e}-\mathrm{i}$ & $14.21 \mathrm{bc}$ & $12.70 \mathrm{de}$ & $12.15 \mathrm{~d}-\mathrm{f}$ & $15.36 \mathrm{ab}$ & $12.62 \mathrm{~d}-\mathrm{f}$ & $14.50 \mathrm{a}-\mathrm{c}$ \\
50 & $10.28 \mathrm{~g}-\mathrm{j}$ & $10.15 \mathrm{~h}-\mathrm{k}$ & $11.43 \mathrm{e}-\mathrm{i}$ & $11.16 \mathrm{f}-\mathrm{i}$ & $11.34 \mathrm{e}-\mathrm{i}$ & $11.49 \mathrm{e}-\mathrm{i}$ & $12.18 \mathrm{~d}-\mathrm{f}$ & $11.68 \mathrm{e}-\mathrm{g}$ \\
100 & $7.03 \mathrm{no}$ & $5.92 \mathrm{o}$ & $6.08 \mathrm{o}$ & $9.43 \mathrm{j}-1$ & $8.68 \mathrm{k}-\mathrm{m}$ & $7.67 \mathrm{mn}$ & $8.151-\mathrm{l}$ & $9.23 \mathrm{j}-1$ \\
150 & $0.90 \mathrm{rs}$ & $1.37 \mathrm{p}-\mathrm{s}$ & $0.76 \mathrm{rs}$ & $2.52 \mathrm{pq}$ & $2.83 \mathrm{p}$ & $1.53 \mathrm{p}-\mathrm{r}$ & $2.84 \mathrm{p}$ & $2.46 \mathrm{pq}$ \\
200 & $0.39 \mathrm{rs}$ & $0.03 \mathrm{~s}$ & $0.16 \mathrm{rs}$ & $1.18 \mathrm{q}-\mathrm{s}$ & $1.19 \mathrm{q}-\mathrm{s}$ & $0.51 \mathrm{rs}$ & $0.82 \mathrm{rs}$ & $0.83 \mathrm{rs}$ \\
\hline
\end{tabular}

Means with same letters have no significant difference, based on LSD Test $(\alpha=0.05)$.

Table 4. Mean comparison of germination components in different wheat cultivars.

\begin{tabular}{|c|c|c|c|c|c|c|c|c|}
\hline $\begin{array}{c}\text { رقمى } \\
\text { Cultivar }\end{array}$ & $\begin{array}{c}\text { وزنه } \\
\text { Radicle } \\
\text { weight } \\
\text { (mg) }\end{array}$ & $\begin{array}{c}\text { وزن ساقه- } \\
\text { وزه } \\
\text { Plumule } \\
\text { weight } \\
\text { (mg) }\end{array}$ & $\begin{array}{c}\text { وزن بذاقدانده } \\
\text { Remaining } \\
\text { seed } \\
\text { weight } \\
\text { (mg) }\end{array}$ & $\begin{array}{c}\text { وزن } \\
\text { وياهجه } \\
\text { Seedling } \\
\text { weight } \\
\text { (mg) }\end{array}$ & 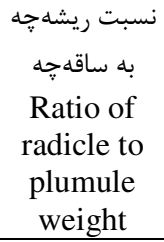 & $\begin{array}{c}\text { يكنواختى جوانه- } ز \text { زنى } \\
\text { Germination } \\
\text { uniformity } \\
\text { (h) }\end{array}$ & $\begin{array}{l}\text { سرعت جوانهزنى } \\
\text { Germination } \\
\text { rate }\left(h^{-1}\right)\end{array}$ & $\begin{array}{c}\text { درصد جوانهزنى } \\
\text { Germination } \\
\text { percentage }\end{array}$ \\
\hline Saysons & $3.9 \mathrm{~d}$ & $5.7 \mathrm{~d}$ & 19.9 & 29.6 & $0.85 \mathrm{a}$ & $53.47 \mathrm{c}$ & $0.0112 \mathrm{~cd}$ & $50.00 \mathrm{c}$ \\
\hline Gaspard & $4.0 \mathrm{dc}$ & $7.1 \mathrm{cb}$ & 27.6 & 38.7 & $0.54 \mathrm{~b}$ & $45.88 \mathrm{ab}$ & $0.0106 \mathrm{~d}$ & $42.66 \mathrm{~d}$ \\
\hline Finkan & $2.5 \mathrm{e}$ & $6.0 \mathrm{~d}$ & 26.3 & 36.9 & $0.57 \mathrm{~b}$ & $36.28 \mathrm{a}$ & $0.0126 \mathrm{ab}$ & $56.93 \mathrm{~b}$ \\
\hline MV-17 & $3.8 \mathrm{~d}$ & $6.4 \mathrm{~cd}$ & 29.6 & 39.9 & $0.66 \mathrm{ab}$ & $47.46 \mathrm{bc}$ & $0.0113 \mathrm{~cd}$ & $50.80 \mathrm{c}$ \\
\hline Chamran & $4.7 \mathrm{~b}$ & $7.0 \mathrm{cb}$ & 16.3 & 28.1 & $0.79 a$ & $42.81 \mathrm{~b}$ & $0.0127 \mathrm{a}$ & $62.90 \mathrm{a}$ \\
\hline Sardari & $4.0 \mathrm{dc}$ & $7.5 \mathrm{ab}$ & 22.5 & 36.1 & $0.56 \mathrm{~b}$ & $49.59 \mathrm{bc}$ & $0.0117 \mathrm{bc}$ & $50.93 \mathrm{c}$ \\
\hline Atila-4 & $5.4 \mathrm{a}$ & $8.0 \mathrm{a}$ & 21.2 & 36.6 & $0.73 a b$ & $50.20 \mathrm{bc}$ & $0.0102 \mathrm{~d}$ & $49.00 \mathrm{c}$ \\
\hline Azar-2 & $4.5 \mathrm{bc}$ & $8.0 \mathrm{a}$ & 20 & 32.5 & $0.75 \mathrm{ab}$ & $48.50 \mathrm{bc}$ & $0.0100 \mathrm{~d}$ & $48.60 \mathrm{c}$ \\
\hline
\end{tabular}


جدول هـ - مقايسه ميانكَينهاى تأثير سطوح مختلف شورى بر مؤلفهاى جوانهزنى كَندم

Table 5. Mean comparison of wheat germination components under salinity stress

\begin{tabular}{|c|c|c|c|c|c|c|c|c|}
\hline $\begin{array}{c}\text { شورى } \\
\text { Salinity } \\
(\mathrm{mM})\end{array}$ & $\begin{array}{c}\text { رزئ } \\
\text { ريشهd } \\
\text { Radicle } \\
\text { weight } \\
\text { (mg) }\end{array}$ & $\begin{array}{l}\text { وزن ساقه- } \\
\text { وزه } \\
\text { Plumule } \\
\text { weight } \\
\text { (mg) }\end{array}$ & $\begin{array}{c}\text { وزن بذاقدانده } \\
\text { Remaining } \\
\text { seed } \\
\text { weight } \\
\text { (mg) }\end{array}$ & $\begin{array}{c}\text { وزن } \\
\text { Seedling } \\
\text { weight } \\
\text { (mg) }\end{array}$ & 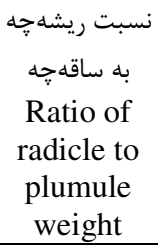 & $\begin{array}{c}\text { يكنواختى جوانه } \\
\text { زنى } \\
\text { Germination } \\
\text { uniformity } \\
\text { (h) }\end{array}$ & $\begin{array}{l}\text { سرعت جوانهزنى } \\
\text { Germination } \\
\quad \text { rate }\left(h^{-1}\right)\end{array}$ & $\begin{array}{c}\text { درصد جوانهزنى } \\
\text { Germination } \\
\text { percentage }\end{array}$ \\
\hline $\begin{array}{c}0 \\
\text { (control) }\end{array}$ & $5.3 \mathrm{~b}$ & $9.6 \mathrm{~b}$ & $11.8 \mathrm{~d}$ & $26.7 \mathrm{c}$ & $0.55 \mathrm{c}$ & $33.32 \mathrm{a}$ & $0.0167 \mathrm{a}$ & $86.33 \mathrm{a}$ \\
\hline 25 & $5.9 \mathrm{a}$ & $10.5 \mathrm{a}$ & $14.4 \mathrm{~cd}$ & $30.9 \mathrm{bc}$ & $0.56 \mathrm{c}$ & $39.84 \mathrm{~b}$ & $0.0137 \mathrm{~b}$ & $71.44 \mathrm{~b}$ \\
\hline 50 & $5.1 \mathrm{~b}$ & $9.6 \mathrm{~b}$ & $15.7 \mathrm{~cd}$ & $30.5 \mathrm{bc}$ & $0.56 \mathrm{c}$ & $53.77 \mathrm{c}$ & $0.0108 \mathrm{c}$ & $56.11 \mathrm{c}$ \\
\hline 100 & $4.0 \mathrm{c}$ & $7.6 \mathrm{c}$ & $2.07 \mathrm{c}$ & $32.4 \mathrm{bc}$ & $0.55 \mathrm{c}$ & $57.40 \mathrm{c}$ & $0.0092 \mathrm{~d}$ & $37.0 \mathrm{~d}$ \\
\hline 150 & $2.5 \mathrm{~d}$ & $3.3 \mathrm{~d}$ & $31.5 \mathrm{~b}$ & $37.2 \mathrm{~b}$ & $0.77 \mathrm{~b}$ & $55.24 \mathrm{c}$ & $0.0080 \mathrm{e}$ & $11.0 \mathrm{e}$ \\
\hline 200 & $1.7 \mathrm{e}$ & $1.3 \mathrm{e}$ & $43.3 \mathrm{a}$ & $46.4 \mathrm{a}$ & $1.10 \mathrm{a}$ & $51.0 \mathrm{c}$ & $0.0001 \mathrm{f}$ & $2.00 \mathrm{e}$ \\
\hline
\end{tabular}

Means with same letters in each column have no significant difference, based on LSD Test ( $\alpha=0.05)$.

و يا حتى در شرايط بدون تنش است كه نمايانگر كارايى

كمتر تبديل مواد ذخيرهاى به تركيبات يويا و ورك

قابلمصرف براى جنين مىباشد (اشرف و همكاران،

(r. r r

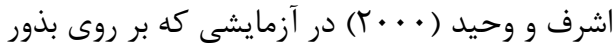

ذرت انجام دادند به اين نتيجه رسيدند كه شورى سبب

محدود شدن ذخاير قندى محلول و در نتيجه اختلال

در متابوليسم تنفسى جنين مىشود. احمد و بانو

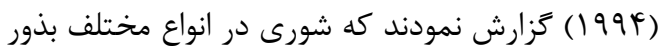
گياهى باعث كاهش هيدروليز و تبديل ذخاير غذايى مىشود كه در نهايت سبب افزايش وزن باقيمانده يس از جوانهزنى مى گردد. بالا بودن وزن كياهجهى حاصل از

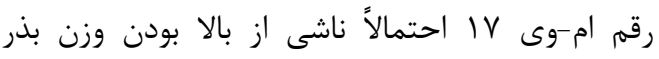
باقيمانده يس از جوانهزنى در اين رقم مىباشد.

\section{طويل ترين ريشه}

نتايج تجزيه واريانس دادهها نشان داد كه رقم و

شورى اثر معنىدارى در سطح ا درصد بر طول طويلترين ريشهجه و ساقه تيمارهاى مورد مطالعه در اين صفات نيز معنى دار بود

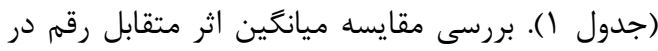
شورى حاكى از آن بود كه رقم سردارى در بين ارقام

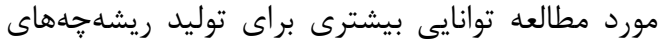

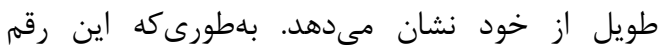
توانست در سطوح شورى صفر و له ميلىمولار طويل-

$$
\begin{aligned}
& \text { رحيميان' و همكاران (1991) نيز عنوان نمودند كه }
\end{aligned}
$$

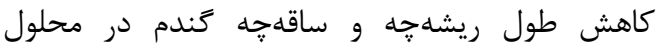

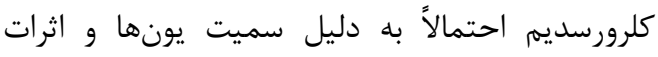

$$
\begin{aligned}
& \text { منفى آنها در غشاى سلولى است. از سوى ديخر ارقام } \\
& \text { ساىسونز و جمران بالاترين نسبت وزن ريشه جه به } \\
& \text { ساقه هِ را به خود اختصاص دادند. كمترين ميزان } \\
& \text { نسبت وزن ريشهجه به ساقهجه در ارقام كاسيارد، } \\
& \text { سردارى و فين كان مشاهده گرديد (جدول f). سطح }
\end{aligned}
$$

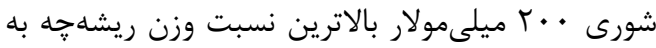

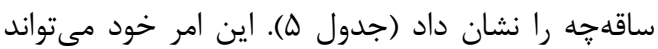

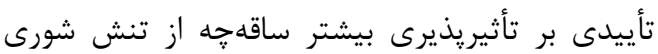

$$
\begin{aligned}
& \text { نسبت به ريشه جه باشد. }
\end{aligned}
$$

\section{وزن بذر باقيمانده يس از جوانهزنى و وزن خشك كياهجه}

هر جند رقم اثر معنى يس از جوانهزنى و وزن گياهجه نشان نداد (جدول ())، ولى رقم ام-وى V Vالاترين ميزان اين صفات را نشان

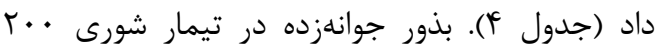

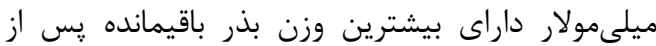

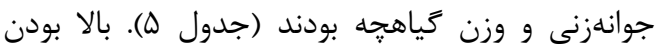
ميزان وزن بذر باقيمانده يس از جوانهزنى نشاندهندهى

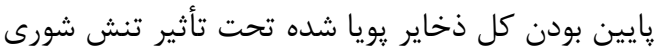

\footnotetext{
${ }^{1}$ Rahimian
} 
ثبات بيشتر از نظر اين صفت در سطوح مختلف شورى،

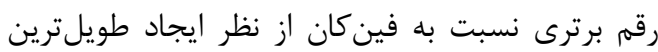
ساقهجه باشد.

صفات طويلترين ريشهجه و ساقه ميزان شورى روندى كاهشى نشان دادند، بلهطورى كه

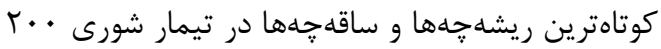

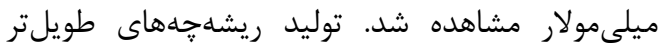

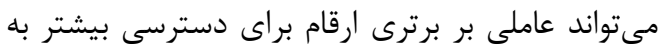

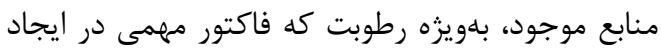

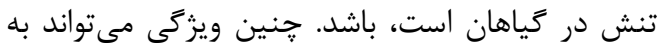

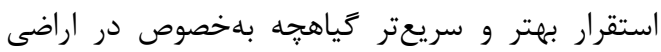
ديم كمك شايانى نمايد.
ترين ريشهجهها را ايجاد نمايد (جدول 9). رقم فين كان نيز در مورد صفت توليد طويلترين ريشهجه كمترين

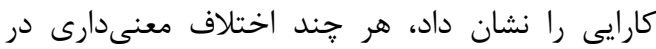

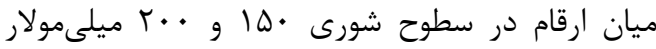

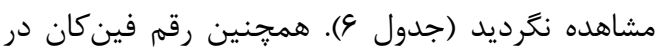

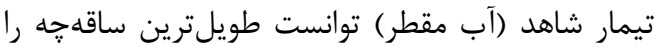

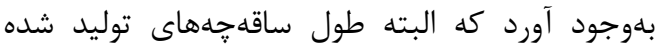

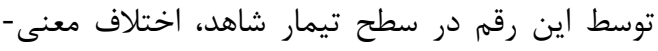

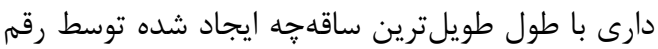
سردارى در سطح شورى

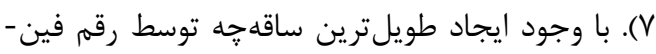
كان، بلنظر مىرسد رقم سردارى بهدليل نشان دادن

جدول 9- مقايسه ميانكَينهاى اثر متقابل شورى در رقم براى صفت طويلترين ريشه حه (سانتمتر) )

Table 6. Mean comparison of interaction effects of salinity and wheat cultivars on the longest radicle $(\mathrm{cm})$

\begin{tabular}{ccccccccc}
\hline $\begin{array}{c}\text { Salinity }(\mathrm{mM}) \\
\text { Saysons }\end{array}$ & Saspard & Finkan & MV-17 & Chamran & Sardari & \multirow{2}{*}{ Atila-4 } & Azar-2 \\
\hline 0 (control) & $13.16 \mathrm{f}-\mathrm{j}$ & $14.16 \mathrm{e}-\mathrm{i}$ & $13.14 \mathrm{f}-\mathrm{j}$ & $17.62 \mathrm{bc}$ & $17.05 \mathrm{~cd}$ & $19.60 \mathrm{~b}$ & $17.78 \mathrm{bc}$ & $16.08 \mathrm{c}-\mathrm{e}$ \\
25 & $11.94 \mathrm{i}-1$ & $14.94 \mathrm{~d}-\mathrm{f}$ & $12.69 \mathrm{f}-\mathrm{j}$ & $16.08 \mathrm{c}-\mathrm{e}$ & $15.87 \mathrm{c}-\mathrm{e}$ & $22.73 \mathrm{a}$ & $17.46 \mathrm{bc}$ & $16.83 \mathrm{~cd}$ \\
50 & $11.48 \mathrm{j}-1$ & $12.31 \mathrm{~g}-\mathrm{k}$ & $9.72 \mathrm{l}-\mathrm{n}$ & $14.52 \mathrm{e}-\mathrm{g}$ & $12.17 \mathrm{~h}-\mathrm{k}$ & $17.09 \mathrm{~cd}$ & $14.20 \mathrm{e}-\mathrm{h}$ & $15.71 \mathrm{c}-\mathrm{e}$ \\
100 & $6.78 \mathrm{op}$ & $5.42 \mathrm{p}$ & $7.10 \mathrm{op}$ & $10.28 \mathrm{k}-\mathrm{m}$ & $7.86 \mathrm{no}$ & $10.32 \mathrm{k}-\mathrm{m}$ & $8.44 \mathrm{~m}-\mathrm{o}$ & $11.78 \mathrm{j}-1$ \\
150 & $1.6 \mathrm{q}$ & $2.53 \mathrm{q}$ & $1.94 \mathrm{q}$ & $2.70 \mathrm{q}$ & $2.40 \mathrm{q}$ & $2.45 \mathrm{q}$ & $2.49 \mathrm{q}$ & $2.88 \mathrm{q}$ \\
200 & $0.7 \mathrm{q}$ & $0.73 \mathrm{q}$ & $0.99 \mathrm{q}$ & $1.48 \mathrm{q}$ & $1.46 \mathrm{q}$ & $1.40 \mathrm{q}$ & $1.61 \mathrm{q}$ & $1.76 \mathrm{q}$ \\
\hline
\end{tabular}

ميانگينهاى داراى حداقل يك حرف مشترك بر اساس آزمون LSD در سطح ينج درصد اختلاف معنى دارى با يكديگر ندارند.

Means with same letters have no significant difference, based on LSD Test $(\alpha=0.05)$.

جدول V - مقايسه ميانكينهاى اثر متقابل شورى در رقم براى صفت طويلترين ساقهجه (سانتىمتر)

Table 7. Mean comparison of interaction effects of salinity and wheat cultivars on the longest plumule (cm)

\begin{tabular}{ccccccccc}
\hline $\begin{array}{c}\text { A } \\
\text { Salinity }(\mathrm{mM})\end{array}$ & Saysons & Gaspard & Finkan & MV-17 & Chamran & Sardari & Atila-4 & Azar-2 \\
\hline 0 (control) & $12.23 \mathrm{~h}-\mathrm{k}$ & $12.00 \mathrm{i}-\mathrm{m}$ & $18.11 \mathrm{a}$ & $13.91 \mathrm{e}-\mathrm{h}$ & $12.46 \mathrm{~h}-\mathrm{k}$ & $15.03 \mathrm{c}-\mathrm{f}$ & $13.24 \mathrm{f}-\mathrm{j}$ & $15.20 \mathrm{c}-\mathrm{e}$ \\
25 & $12.63 \mathrm{~h}-\mathrm{k}$ & $12.96 \mathrm{~g}-\mathrm{j}$ & $16.03 \mathrm{bc}$ & $14.06 \mathrm{~d}-\mathrm{h}$ & $14.63 \mathrm{c}-\mathrm{g}$ & $17.53 \mathrm{ab}$ & $14.00 \mathrm{~d}-\mathrm{h}$ & $15.83 \mathrm{~b}-\mathrm{d}$ \\
50 & $11.36 \mathrm{j}-\mathrm{n}$ & $11.40 \mathrm{j}-\mathrm{n}$ & $14.62 \mathrm{c}-\mathrm{g}$ & $12.70 \mathrm{~h}-\mathrm{k}$ & $13.63 \mathrm{e}-\mathrm{i}$ & $14.70 \mathrm{c}-\mathrm{g}$ & $14.01 \mathrm{~d}-\mathrm{h}$ & $15.01 \mathrm{c}-\mathrm{f}$ \\
100 & $8.40 \mathrm{op}$ & $7.93 \mathrm{p}$ & $7.76 \mathrm{p}$ & $11.01 \mathrm{k}-\mathrm{n}$ & $10.16 \mathrm{~m}-\mathrm{o}$ & $10.03 \mathrm{no}$ & $10.431-\mathrm{n}$ & $11.36 \mathrm{j}-\mathrm{n}$ \\
150 & $1.71 \mathrm{t}-\mathrm{w}$ & $2.21 \mathrm{~s}-\mathrm{v}$ & $1.40 \mathrm{u}-\mathrm{w}$ & $3.61 \mathrm{q}-\mathrm{s}$ & $4.23 \mathrm{q}$ & $2.33 \mathrm{r}-\mathrm{u}$ & $4.14 \mathrm{qr}$ & $3.22 \mathrm{q}-\mathrm{t}$ \\
200 & $0.62 \mathrm{u}-\mathrm{w}$ & $0.06 \mathrm{w}$ & $0.36 \mathrm{vw}$ & $1.63 \mathrm{t}-\mathrm{w}$ & $2.00 \mathrm{~s}-\mathrm{v}$ & $0.82 \mathrm{u}-\mathrm{w}$ & $1.46 \mathrm{t}-\mathrm{w}$ & $1.60 \mathrm{t}-\mathrm{w}$ \\
\hline
\end{tabular}

ميانگينهاى داراى حداقل يك حرف مشترك بر اساس آزمون LSD در سطح ينج درصد اختلاف معنى دارى با يكديكر ندارند.

Means with same letters have no significant difference, based on LSD Test ( $\alpha=0.05)$. 
يزوهشهاى بذر ايران / سال جهارم/ شماره دوم/ ع وسا

جدول ^- مقايسه ميانگَينهاى اثر متقابل شورى در رقم براى صفت ميانگَين تعداد ريشه جه در بذر

Table 8. Mean comparison of interaction effects of salinity and wheat cultivars on the number of the radicle

\begin{tabular}{|c|c|c|c|c|c|c|c|c|}
\hline $\begin{array}{c}\text { شورى } \\
\text { Salinity (mM) }\end{array}$ & Saysons & Gaspard & Finkan & MV-17 & Chamran & Sardari & Atila-4 & Azar-2 \\
\hline 0 (control) & 4.4 a-e & $4.4 \mathrm{a}-\mathrm{e}$ & $3.5 \mathrm{f}-\mathrm{k}$ & $3.8 \mathrm{~d}-\mathrm{i}$ & $4.8 \mathrm{ab}$ & $3.2 \mathrm{~h}-\mathrm{k}$ & $4.8 \mathrm{ab}$ & $3.1 \mathrm{~h}-\mathrm{m}$ \\
\hline 25 & $4.8 \mathrm{ab}$ & $4.6 \mathrm{a}-\mathrm{c}$ & $3.1 \mathrm{~h}-\mathrm{m}$ & $3.4 \mathrm{~g}-\mathrm{k}$ & $4.8 \mathrm{ab}$ & $3.2 \mathrm{~h}-\mathrm{k}$ & 4.4 a-e & $3.2 \mathrm{~h}-\mathrm{k}$ \\
\hline 50 & $4.2 \mathrm{~b}-\mathrm{f}$ & $4.3 \mathrm{a}-\mathrm{e}$ & $3.6 \mathrm{e}-\mathrm{j}$ & $3.6 e-j$ & $4.8 \mathrm{ab}$ & $3.3 \mathrm{~h}-\mathrm{k}$ & $4.3 \mathrm{a}-\mathrm{e}$ & $3.4 \mathrm{~g}-\mathrm{k}$ \\
\hline 100 & $3.8 \mathrm{~d}-\mathrm{i}$ & $4.3 \mathrm{a}-\mathrm{e}$ & $3.3 \mathrm{~h}-\mathrm{k}$ & $3.8 \mathrm{~d}-\mathrm{i}$ & $5.0 \mathrm{a}$ & $3.2 \mathrm{~h}-\mathrm{k}$ & $4.5 \mathrm{a}-\mathrm{d}$ & $3.2 \mathrm{~h}-\mathrm{k}$ \\
\hline 150 & $3.8 \mathrm{~d}-\mathrm{i}$ & $3.0 \mathrm{i}-\mathrm{m}$ & $2.8 \mathrm{k}-\mathrm{m}$ & $3.8 \mathrm{~d}-\mathrm{i}$ & $4.1 \mathrm{~b}-\mathrm{g}$ & $2.9 \mathrm{j}-\mathrm{m}$ & $4.2 \mathrm{~b}-\mathrm{f}$ & $3.5 \mathrm{f}-\mathrm{k}$ \\
\hline 200 & $1.9 \mathrm{n}$ & $2.4 \mathrm{mn}$ & $2.41-n$ & $3.3 \mathrm{~h}-\mathrm{k}$ & $3.8 \mathrm{c}-\mathrm{h}$ & $3.1 \mathrm{~h}-\mathrm{m}$ & $3.2 \mathrm{~h}-1$ & $2.9 \mathrm{j}-\mathrm{m}$ \\
\hline
\end{tabular}

ميانگينهاى داراى حداقل يك حرف مشترك بر اساس آزمون LSD در سطح ينج درصد اختلاف معنىدارى با يكديگر ندارند.

Means with same letters have no significant difference, based on LSD test ( $\alpha=0.05)$.

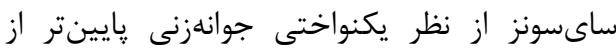
ساير ارقام قرار كرفت (جدول عأ). رقم جمران بالاترين ميزان سرعت و درصد جوانهزنى را به خود اختصاص داد ادراد كه بلنوعى نشانَر توانايى اين رقم از نظر قدرت جوانه-

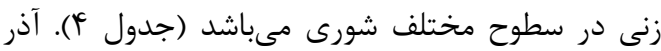

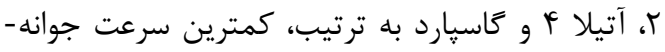
زنى را نشان دادند. همجنين كاسيارد نسبت به ساير

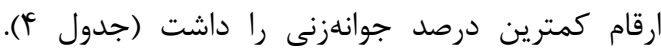
افزايش ميزان شورى سبب كاهش خشمَّيرى در

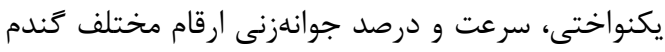

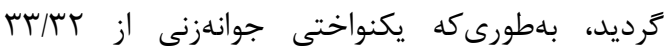
(ساعت)، سرعت جوانهزنى از I I • • • (ساعت) و درصد

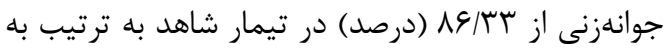

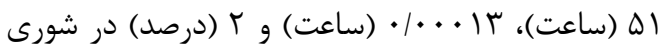

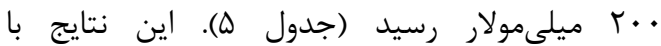

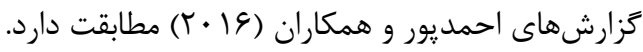

بهاطور كلى مىتوان نتيجه كرفت، افزايش شدت

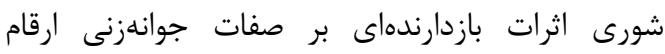
مختلف كَندم دارد. از سوى ديخر عكسالعمل ارقار ارقام نيز

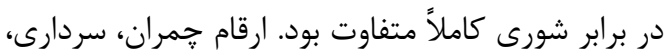

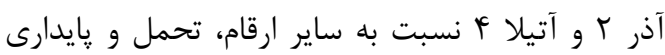
بيشترى در مقابل تنش شورى از خود نشان دادند. توجه

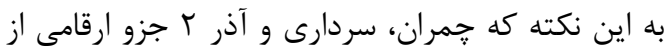

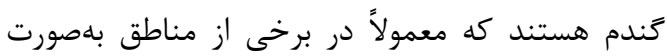

\section{ميانگين تعداد ريشهجه در هر بذر}

تعداد ريشهجههاى ايجاد شده توسط بذر بهنئكام جوانهزنى از صفات مهمى است كه ميتواند به استقرار بهتر كياهجه بهخصوص تحت شرايط تنش، كمك نمايد.

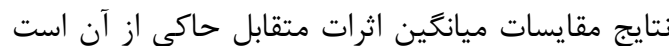
كه افزايش سطح شورى سبب كاهش ميانكين تعداد ريشه קه توليدى توسط هر بذر مىشود، بلططورى كه در

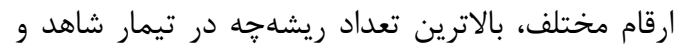

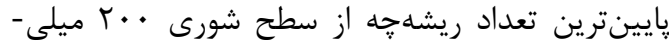
مولار حاصل گرديد. رقم جمران از نظر توليد تعداد

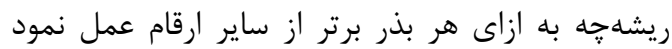

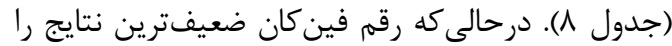

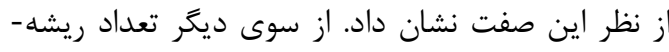
جههاى توليدى توسط هر رقم در سطوح مختلف شورى آرى

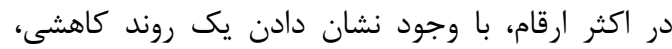
تفاوت معنىدارى نشان نداد كه اين امر مىتواند دليلى إنى

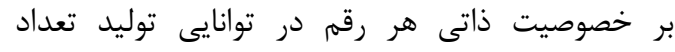
مشخصى ريشه קه در شرايط متفاوت باشد. جاووشوقلو و

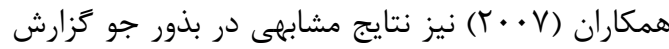
نمودهاند.

\section{يكنواختى، سرعت و درصد جوانهزنى}

نتايج تجزيه واريانس دادهها حاكى از آن بود كه رقم دورات

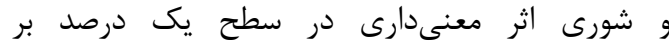

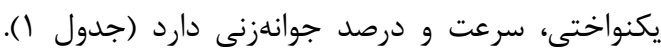
فينكان بالاترين ميزان يكنواختى جوانهزنى را نشان داد كه البته اختلاف معنى دارى با كاسيارد نداشت. 


$$
\begin{aligned}
& \text { اين نتايج مىتوان رقم مناسب را براى كشت در هر } \\
& \text { منطقه با در نظر زرفتن شرايط حاكم بر منطقه، خصوصاً }
\end{aligned}
$$

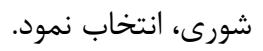

$$
\begin{aligned}
& \text { IV ديم كشت مىشوند، بسيار حائز اهميت است. ام-وى }
\end{aligned}
$$

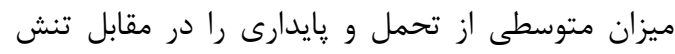

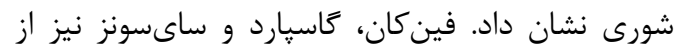

$$
\begin{aligned}
& \text { اين نظر ضعيفتر از ساير ارقام ظاهر شدند. با توجه به نهان }
\end{aligned}
$$

منابع

Ahmad, J., and Bano, M. 1994. The effect of sodium chloride on the physiology of cotyledon and mobilization of reserve food in Cicer arientinum. Pakistan Journal of Botany, 24(1): 40-48.

Ahmadpour, R., Armand, N., and Hossinzadeh, S.R. 2016. Effect of vermicompost extract on germination characteristics of chickpea (Cicer arietinum) under salinity stress. Iranian Journal of Seed Research, 2(2):123-135. [In Persian with English abstract].

Alam, S.M., Khan, M.A., Mujtaba, S.M., and Shereen, A. 2002. Influence of aqueous leaf extract of common lambsquarters and $\mathrm{NaCl}$ salinity on the germination, growth and content of wheat. Acta Physiologiae Plantarum, 24(4): 359-364. https://doi.org/10.1007/s11738-002-0030-8

Ashraf, M.Y., and Wahid, S. 2000. Time course changing in organic metabolites and mineral nutrients in germination maize seeds under salt $(\mathrm{NaCl})$. Seed Science and Technology, 28(3): 641-656.

Ashraf, M.Y., Sarwar, G., Ashraf, M., Afaf, R., and Satar, A. 2002. Salinity induced changes $\alpha-$ amylase activity during germination and early cotton seedling growth. Biologia Plantarum, 45(4): 589-591. https://doi.org/10.1023/A:1022338900818

Azarnivand, H., and Jafarian, Z. 2003. Effects of salinity on germination of Agropyron desertorum and Agropyrun cristatim. Desert Journal, 1(8): 52-62. [In Persian with English Summary].

Cavusoglu, K., Kilic, S. and Kabar, K. 2007. Some morphological and anatomical observation during alleviation of salinity $(\mathrm{NaCl})$ stress on seed germination and seedling growth of barley by polyamines. Acta Physiologiae Plantarum, 29(6): 551-557. https://doi.org/10.1007/s11738-007-0066-X

Dash, M., and Panda, S.K. 2001. Salt stress induced changes in growth and enzyme activities in germination Phaseolus mungo seed. Biologia Plantarum, 44: 587-589. https://doi.org/10.1023/A:1013750905746

Dehganzadeh, H., Sanjari, Sh. and Afsharmanesh, Gh. 2012. Effects of salt stress on germination indices of wheat cultivars. Plant and Ecosystem, 8(30): 89-98. [In Persian with English Summary].

Dehshiri, A. 1998. Response of rapeseed cultivars to water stress. M.Sc. Thesis Agriculture Department. Tarbiat Modares University. [In Persian with English Summary].

El-Mashad, A.A., and Kamel, E.A. 2001. Amelioration of $\mathrm{NaCl}$ stress in Pisum sativum L. International Journal of Experimental Biology, 39: 469-475.

Galeshi, S., Soltani, A., and Zeinali, E. 2001. Germination, seed reserve utilization and seedling growth of chickpea as affected by salinity and seed size. Seed Symposium. In 26th Congress of the International Seed Testing Association (ISTA). Anger, France, P.12.

Gholinejhad, A. 2011. Effects of salinity stress on germination indices of wheat genotypes. Iranian Journal of Seed Science and Technology, 1(1): 14-21. [In Persian with English Summary].

Ghoulam, C., and Fares, K. 2001. Effect of salinity on seed germination and early seedling growth of sugar beet (Beta vulgaris L.). Seed Science and Technology, 29(2): 357-364. 
Hadi, H., Seyed Sharifi, R., and Namvar, A. 2016. Phytoprotectants and abiotic stresses. Urmia University Publication. 341p. [In Persian].

Hussain, S.A., Akhtar. J., Anwar-ul-haq. M., and Ahmad, R. 2011. Growth, yield and ionic concentration of two sunflower (Helianthus annuus L.) genotypes exposed to brackish water irrigation. Soil and Environment, 30(1): 58-65.

Khodarahmpour, Z. 2011. Screening maize (Zea mays L.) hybrids for salt stress tolerance at germination stage. African Journal Biotechnology, 10(71): 15959-15965. https://doi.org/10.5897/AJB11.2493

Mostafavi, K. 2011. An evaluation of safflower genotypes (Carthamus tinctorius L.), seed germination and seedling characters in salt stress conditions. African Journal of Agricultural Research, 6(7): 1667-1672.

Moussavi-Nik, M., Babaeian, M., and Tavassoli, A. 2011. Effect of seed size and genotype on germination characteristic and seed nutrient content of wheat. Scientific Research and Assays, 6: 2019-2025. https://doi.org/10.5897/SRE11.621

Namvar, A., Seyed Sharifi, R., Khandan, T., and Molaei, P. 2009. Influence of extracts of Chenopodium album and $\mathrm{NaCl}$ salinity on germination and seedling growth of soybean. Allelopathy Journal, 23(1): 193-202.

Rahimian, H., Bagheri Kazem Abad, A. and Paryab, A. 1991. Effects of different potential of PEG and $\mathrm{NaCl}$ in combination with temperature on germination of wheat. Agricultural Sciences and Industry, 5(1): 37-42. [In Persian with English Summary].

Shakeri, R., Tobeh, A., and Jamaati, Sh. 2013. Study the effects of seed priming on germination indices of wheat under salinity stress. Seed Research Journal, 3(4): 8-19. [In Persian with English abstract].

Tazikeh, N., Dadashi, M., and Jafari, M. 2013. Study of germination of two wheat cultivars under salinity stress. Seed Research Journal, 3(4): 1-7. [In Persian with English Summary].

Valadiani, A., Hassanzadeh, A., and Tajbakhsh, M. 2005. Study on the effects of salt stress in germination and embryo growth stages of the four prolific and new cultivars of winter rapeseed (Brassica napus L.). Pajouhesh \& Sazandegi, 66: 23-32. [In Persian with English Summary]. 


\title{
A Study into the Effects of Salt Stress on Germination Components of Different Wheat (Triticum aestivum) Cultivars
}

\author{
Ali Namvar ${ }^{1 *}$, Raouf Seyed Sharifi ${ }^{2}$, Hashem Hadi ${ }^{3}$ \\ ${ }^{1}$ Ph.D. Student of Crop Physiology, Department of Agronomy, Urmia University, Urmia, Iran \\ ${ }^{2}$ Professor of Department of Agronomy and Plant Breeding, University of Mohaghegh Ardabili, \\ Ardabil, Iran \\ ${ }^{3}$ Assistant Professor, Department of Agronomy, Urmia University, Urmia, Iran \\ "Corresponding author, E-mail address: Namvar_a60@yahoo.com
}

(Received: 19.10.2016; Accepted: 09.10.2017)

\begin{abstract}
In order to study the effects of different levels of salinity on germination components of wheat cultivars, a factorial experiment was conducted based on a completely randomized design with three replications. Experimental factors were wheat cultivars at eight levels (Saysons, Gaspard, Finkan, MV-17, Chamran, Sardari, Atila-4 and Azar-2) and six levels of salinity (0, 25, 50, 100, 150 and $200 \mathrm{mM} \mathrm{NaCl}$ ). The results indicated that salinity had significant effects on all of the traits studied (i.e., radicle length and dry weight, plumule length and dry weight, remaining seed weight after germination, seedling weight, the longest radicle and plumule, number of radicle per seed, ratio of radicle weight to plumule weight and rate, and uniformity and percentage of germination). All of these traits declined with an increase in the salinity (except the ratio of radicle weight to plumule weight, remaining seed weight after germination and seedling weight). The highest ratio of radicle weight to plumule weight, remaining seed weight after germination and seedling weight were recorded in the salinity of $200 \mathrm{mM} \mathrm{NaCl}$. The cultivars showed significant effects on all of the traits studied (except remaining seed weight after germination and seedling weight). Chamran cultivar showed the highest number of radicle per seed, the ratio of radicle weight to plumule weight, rate and percentage of germination. The highest radicle length and the longest radicle were obtained from the Sardari cultivar while in Azar-2 cultivar it was vice versa in plumule. Atila-4 cultivar showed the highest radicle and plumule weight. It seems that compared with other cultivars, out of the cultivars studied, Chamran, Azar-2, Sardari and Atila-4 were more resistant to salinity stress.
\end{abstract}

Keywords: Number of radicle, Remaining seed weight after germination, Salt stress, Wheat cultivars

\section{Highlights:}

1- Introduction of wheat cultivars with more tolerance to salinity conditions at germination stage.

2- Study of eight different wheat cultivars in terms of germination indices under salinity stress conditions.

DOI: $10.29252 /$ yujs.4.2.1

CrossMark 